Sicologia \& Sociedade; 14 (1): 123-140; jan./jun.2002

\title{
"À FELICIDADE NA LIBERDADE OU À FELICIDADE NA AUSÊNCIA DE LIBERDADE”"1
}

\author{
Kety Valéria Simões Franciscatti \\ Pontifícia Universidade Católica de São Paulo
}

Resumo: Nessa sociedade que se reproduz em torno da dominação, a psicologia traz, como disciplina parcelar, a possibilidade de voltar-se para a contenção da violência e a tendência de repor os elementos da barbárie. Faz parte desta última, mascarar os fatores objetivos que a determinam e, o contrário, reside em pesquisar as condições subjetivas que sustentam a irracionalidade objetiva, com clareza de que crítica ao conhecimento deve ser crítica da sociedade. A psicologia fica sem respostas e não sabe, resignada em não investigar a dialética que desvela o antagonismo social, de seu propósito tal como é remetido na frase de Adorno no texto escrito em 1955 e indicada como título deste ensaio. No específico, mesmo cego ante a totalidade que o compõe e que constitui, encontra-se traços da verdade do progresso como denúncia do que pode mas não foi efetivado. Alcançar a liberdade e a felicidade faz parte da tarefa objetiva de superar os ditames da autoconservação. Entretanto, os homens encontram-se impotentes e resistir significa conhecer os limites da prisão. É ideológico atribuir à psicologia o trabalho direto com o sofrimento; deve-se combater aquilo que causa o sofrimento e não manter as formas de ilusão.

Palavras-chaves: violência, teoria crítica da sociedade, psicologia social, indivíduo, trabalho, sexualidade.

\section{HAPPINESS IN FREEDOM OR HAPPINESS OUT OF FREEDOM}

ABSTRACT: In a society that reproduces itself within a domination pattern, psychology as a multisided discipline provides the possibility of containing both violence and the tendency of replacing barbarity. The latter masks its self-generating objective factors, whereas its opponent searches for the subjective conditions maintaining the objective irrationality, and so understands that the critic of knowledge must be the critic of society. Psychology has no answers and at the same time refuses to investigate the dialectics that would uncover social antagonism, in the way that is indicated 
Franciscatti, K.V.S. "À felicidade na liberdade ou à felicidade na ausência de liberdade"

in Adorno's sentence, written in 1955, that is the title of this essay. Although being completely blind about the elements generating totality, one might find signs of truly progress indicating that, although something was possible, it was never brought to be effective. Reaching freedom and happiness might be an objective task in a way to overcome rules of self-conservation. Nevertheless, human beings find themselves completely lost and the only possible way of resist rests upon knowing the limits of prison. The thought that psychology should be responsible for working directly with suffering is ideological; it is necessary to struggle against what produces suffering and not to create ways of maintaining the illusion that the suffering does not exist.

KEY WORDS: violence, critical theory of society, social psychology, individual, labour, sexuality.

\section{ESCLARECIMENTO, CIÊNCIA E TECNOLOGIA}

Em uma sociedade que se reproduz em torno da dominação fazse necessário investigar para onde a ciência caminha ao aderir e responder às suas exigências imediatas. Segundo Adorno e Horkheimer (1994, p.19), emancipação e conhecimento estão relacionados em um eixo comum chamado esclarecimento e, no sentido mais amplo do progresso do pensamento, tem buscado sempre o objetivo de livrar os homens do medo e de torná-los senhores de si, de superar os mitos e as distorções da imaginação sobre a realidade através do saber: seu programa tinha como meta desencantar o mundo. Contudo, os autores afirmam que o próprio esclarecimento contém, em sua dinâmica, elementos progressivos e regressivos, que possibilitam e dificultam aos homens essa capacidade e, nesse sentido, "o mito já é esclarecimento e o esclarecimento acaba por reverter à mitologia" (op. cit.,p.15).

Assim, se o conhecimento, por meio da reflexão sobre a sociedade, pode levar a transformações das formas de organização social e de constituição humana, o progresso, no entanto, caracterizado pelas formas de dominação e poder, ainda segue o curso que conserva e arrasta uma "catástrofe histórica" (op. cit.,p.59). O conhecimento, ao ceder aos elementos regressivos presentes na realidade e que também o compõe, mantém e propaga o progresso da dominação e sua "irrefreável regressão" (op. cit.,p.46). 
Psicologia \& Sociedade; 14 (1): 123-140; jan./jun.2002

A tendência do próprio pensamento crítico aderir àquilo que critica torna-se patente quando as ciências são reduzidas a simples técnicas e os cientistas a produtores de tecnologia com fins de aplicação imediata. Perigo cada vez mais objetivo em que impera a falta de reflexão orientada com a finalidade de uma vida humana. Adorno (1995a), fundamentado em Freud, indica como as "próteses", extensões dos órgãos (sentidos e motores) humanos, são tomadas como fins em si mesmas esquecendose de que são elementos auxiliares do corpo humano:

“(...) na relação atual com a técnica, há algo de excessivo, irracional, patógeno. Esse algo está relacionado com o véu tecnológico. As pessoas tendem a tomar a técnica pela coisa mesma, a considerá-la um fim em si, uma força com vida própria, esquecendo, porém, que ela é o prolongamento do braço humano. Os meios - e a técnica é a mais alta representação dos meios para a autoconservação da espécie humana - são fetichizados porque os fins, uma vida humana digna, têm sido velados e expulsos da consciência das pessoas". (Adorno, 1995a, p.118; grifos no original)

Na ponta das produções científicas, impulsionados por financiamentos de agências públicas e/ou particulares, são fortalecidos os conhecimentos que geram aplicações imediatas e lucrativas, marcados pelos interesses da ideologia - entendida como justificação de dominação e desigualdade - e que não realizam a verdadeira ciência que se quer crítica. Horkheimer e Adorno (1973, p.129) indicando os limites da sociologia, mas que são extensivos a todas as ciências sociais, alertam: para produzir um conhecimento crítico é necessário enfrentar tanto os limites da sociedade que se quer transformar, como das condições sociais que possibilitam a formação deste mesmo conhecimento. Assim, é preciso tomar o conhecimento como objeto de reflexão em seu confronto com a realidade, pois, ao não realizar esta tarefa, as ciências sociais acabam servindo aos interesses da manipulação e conservação social, e, uma teoria “(...) em que a transformação não seja apenas uma frase domingueira deve integrar a fatualidade, em toda a sua força de resistência, sob pena de continuar sendo apenas um sonho impotente, cuja impotência só beneficia, uma vez mais, o poder do que está estabelecido" (op. cit., p.130).

Se a constatação da fetichização da técnica não deve levar à sua condenação e eliminação, mas ao resgate de sua finalidade, do mesmo modo a ciência - que pela sua aplicabilidade vem sucumbido a este processo de fetichismo tecnológico - também deve, ao dedicar-se à crítica sobre si 
Franciscatti, K.V.S. "À felicidade na liberdade ou à felicidade na ausência de liberdade"

mesma, retomar-se como meio de atingir os fins de uma vida livre, justa e digna. "Crítica não significa, neste caso, subjetivismo mas confronto da coisa com o seu próprio conceito" porque, na medida em que, não se "(...) compara as coisas humanas com o que elas querem significar, vê-as não só de uma forma superficial mas definitivamente falsa" (op. cit., p.21).

A preocupação e o cuidado com a produção de um conhecimento crítico deve estar contida na atividade dos cientistas sociais. Por isso é fundamental pesquisar como a violência é abordada pelo conjunto das ciências sociais, mais especificamente neste caso, como a psicologia inscreve sua contribuição em seu próprio campo. Trazer a crítica à psicologia e seu objeto de estudo também expõe, de maneira mais ampla, os problemas da organização do trabalho científico, em que a divisão dos campos das ciências acaba ocultando o objeto que se quer estudar.

"A sociologia pura não existe, tal como não existe uma história pura, uma psicologia ou uma economia pura; o próprio substrato da psicologia - o Indivíduo - não passa de uma abstração, se o retirarmos das suas determinantes sociais. Não é possível ignorar a divisão científica do trabalho sem provocar o caos; entretanto, as suas divisões não se identificam, por certo, com a estrutura da própria coisa". (op. cit., pp.20-21)

O que parece imperar nos estudos sobre a violência é a indiferenciação pois tratam, sem nomear, do psicológico, desconsiderando a relação entre os aspectos objetivos e subjetivos, obstruindo, nesse movimento, o esclarecimento sobre as condições que perpetuam a manifestação da violência. Nesse sentido, reafirmar que o indivíduo tal como prometido no esclarecimento - capaz de auto-reflexão e autodeterminação - é o objeto da psicologia é ainda permitir a existência de sua promessa como negação da realidade que o impede.

\section{SOCIEDADE E INDIVÍDUO}

A psicologia traz, como disciplina parcelar, a possibilidade de voltar-se para a contenção da violência e a tendência de repor os elementos da catástrofe histórica que se arrasta com os homens. Faz parte dessa última tendência, não nomear ou mascarar os fatores objetivos que determinam a barbárie e, o contrário, reside em investigar “(...) as condições subjetivas da irracionalidade objetiva" (Adorno, 1986, p.36 e 1991, p.136) com a clareza de que "crítica da sociedade é crítica do conhecimento, e vice-versa" (Adorno, 1995b, p.189). A ciência psicológica fica sem res- 
Psicologia \& Sociedade; 14 (1): 123-140; jan./jun.2002

postas e não sabe, e nem pode saber, cega e resignada em não investigar a dialética que desvela o antagonismo social, de seu propósito tal como é remetido na frase de Adorno, no texto "Acerca de la relación entre sociologia y psicologia" (escrito em 1955) em crítica direta à terapia, mas indicada como título deste ensaio em relação à psicologia em geral: "o antagonismo social se reproduz no objetivo da análise, a qual já não sabe nem pode saber para onde quer levar o paciente, à felicidade na liberdade ou à felicidade na ausência de liberdade" (1986, p. 73 e 1991, p. 199).

Apesar dos avanços da sociedade, atribuídos, na maioria das vezes, às áreas da ciência e da tecnologia, recai sobre os homens a continuidade do horror e seus sofrimentos, o mal-estar tão bem relatado por Freud, que pergunta: "enfim, de que nos vale uma vida longa se ela se revela difícil e estéril em alegrias, e tão cheia de desgraças que só a morte é por nós recebida como uma libertação?" (1974, p.108)

A persistência desse horror e o vazio teórico das repetições superficiais levam as ciências parcelares a intensificarem as tentativas de integração e até de abandono de seus objetos de estudo. Segundo Adorno (1986 e 1991), a confiança na integração das ciências expressa desamparo, expressa o progresso da regressão do esclarecimento. No específico, mesmo que cego ante a totalidade que o compõe e que constitui, encontrase traços da verdade do progresso como denúncia do que pode mas ainda não foi efetivado.

Alardeado em toda parte, o indivíduo perde-se no individualis$m o$, anulando as capacidades contidas em seu próprio conceito: quanto mais se fala de sua existência mais se desvela sua reificação. Por outro lado, ocorre a exacerbação de uma espécie de sociologismo, em que as categorias sociais como grupo, comunidade e massas, são preferidas em detrimento do que pode significar o conceito de indivíduo. Sem considerar a cisão da realidade, cria-se a ilusão de que através da produção do conhecimento - neste caso ideologia - torna-se possível resolver os impedimentos da realização do indivíduo. No mundo administrado, ocorre a reificação da consciência que adere ao jogo da dominação: a coisa se torna dona do seu senhor, que se abandona enfurecido contra a própria promessa contida na cultura que o constitui.

No texto escrito em 1955, Adorno elogia a psicanálise de Freud como a única psicologia que proporciona condições de analisar os aspectos subjetivos que sustentam a irracionalidade objetiva. No entanto, ela não é apresentada, neste e em outros textos, isenta de críticas, seus limites e seu anacronismo são tratados com todo rigor. Por isso mesmo, a ciência 
Franciscatti, K.V.S. "À felicidade na liberdade ou à felicidade na ausência de liberdade"

parcelar proposta por Adorno é a "psicologia social analiticamente orientada" que, dessa forma, e, juntamente com uma teoria da sociedade, seriam capazes de explicar a derrocada representada pelo fascismo.

Se "a verdade do todo descansa na unilateralidade" (op. cit., p.39 e op. cit., p.140) a psicologia traz a sua ao demonstrar que "a irracionalidade do sistema racional se manifesta na psicologia do sujeito cativo" (op. cit., p.42 e op. cit., p.145), no anacronismo que é vivido a cada dia em uma sociedade que mantém suas formas de organização aquém do que já foi alcançado por seu desenvolvimento material, o que impõe aos homens diversos sacrifícios inúteis. Freud (1974, p.137) pôde indicar o quanto os homens abrem mão de parte de sua felicidade para ter segurança através da cultura. A cultura tem em seu projeto tanto a promessa de segurança como de realização das pulsões, promessa que no entanto ainda não está realizada. $\mathrm{O}$ que existe é uma sociedade ${ }^{2}$ que vem funcionando independente da felicidade dos homens, que passa a ser um fim em si mesma e coloca os homens como meio, processo em que seus desejos são acionados para a opressão e não em sua realização. Dessa forma, não é sem participação dos homens que a dominação progride. Postular uma imagem de homem bom mas acorrentado ou de um homem mau que acorrenta é prestar serviço aos grilhões. Não é mera retórica afirmar que "toda imagem do homem, com exceção da negativa, é ideologia" (Adorno, 1986, p.59 e 1991, p.175), é constatação teórica e empírica.

De acordo com Adorno (1986 e 1991), o mais decisivo para a compreensão dos fatores subjetivos que sustentam a irracionalidade objetiva é a compreensão do medo, de seus desdobramentos dentro do processo histórico de dominação que vem constituindo a segunda natureza humana até os dias de hoje. É o medo que fundamenta o comportamento economicamente racional - a escolha do mal menor - e o comportamento propriamente psíquico com que os homens respondem às demandas da racionalidade objetiva. Estes expressam as marcas do sofrimento que denunciam a farsa da integração da sociedade.

O medo é resultado da possibilidade de se diferenciar do mundo indiferenciado; é o responsável por todos os mecanismos de defesa. Adorno descreve dois tipos de medo. Um medo mais antigo e originário de ser destruído, de ter sua existência física colocada em risco ante os perigos de uma natureza desconhecida. É ele que orienta para a vida na tarefa da autoconservação. E um medo mais recente, internalizado pelos homens e convertido em segunda natureza, sentido diante da ameaça de deixar de pertencer à unidade social que deveria proteger seus membros da ameaça 
Psicologia \& Sociedade; 14 (1): 123-140; jan./jun.2002

inicial da natureza. O segundo, o de ser expulso da sociedade, é associado ao medo mais antigo e este, o primeiro, que é o de ser aniquilado, não pode ser reprimido e deveria, em uma sociedade justa, ser elaborado. Porém, na presente, é mantido e renovado com a incorporação da ameaça tal como sentida anteriormente.

As formas de ofuscamento e distorção do medo estão em toda parte. Ao ser negada sua elaboração, seus elementos voltam com mais força traduzindo-se nos mecanismos psicológicos colocados em ação para realizar as exigências, ainda que infundadas, da autoconservação. Todavia, o perigo é objetivo e repõe a ameaça que alimenta o medo; mas dito desta forma ainda não basta, falta um complemento: "do mundo tal qual é, ninguém poderá atemorizar-se suficientemente" (Adorno, 1995c, p.225).

"A divergência entre indivíduo e sociedade é essencialmente de origem social, é perpetuada socialmente e suas manifestações têm por princípio de ser explicadas socialmente" (Adorno, 1986, p.43 e 1991, p.148). Porém, é por meio da possibilidade do indivíduo que a sociedade se diferencia da natureza, quanto mais possível for a individuação maior a diferenciação da sociedade. E é certo também que, se a diferenciação entre indivíduo e sociedade é social na origem, a indiferenciação não é menos.

Verdadeira e falsa a cisão entre indivíduo e sociedade indica também a verdade e a falsidade na cisão entre psicologia e sociologia. A primeira, entre indivíduo e sociedade, é falsa porque os indivíduos não se constituem fora da sociedade e esta não existe sem indivíduos, e é verdadeira porque vem se tornando real uma vez que não há o reconhecimento dos indivíduos na sociedade que o compõe e esta, por sua vez, impõem suas forças por cima dos indivíduos negando-lhes as condições e as oportunidades da diferenciação. A segunda, entre psicologia e sociologia, tem sua verdade ao indicar que o conflito ocorre na realidade não reduzindo-o à esfera da produção do conhecimento, na busca ilusória de uma união conceitual, e sua falsidade ao defender a renúncia ao conhecimento da totalidade que, por sua vez, determina a separação ${ }^{3}$.

O homem é mediação social mas ainda tem sua consciência como se fosse uma mônada ${ }^{4}$. Portanto, o mérito da psicanálise de Freud. A insistência na mônada traz a possibilidade de estourar seu aspecto de falsidade, mostrando no particular aquilo que de social o constitui, revela indícios da potencialidade do conhecimento especializado. Nele há possibilidades de trazer à luz a presença do todo, pois no limite a especialização é o seu oposto. Ao exagerar explode e mostra a determinação social. A psicanálise, ao fechar os olhos para a sociedade e nisso trazer a sociedade introjetada 
Franciscatti, K.V.S. "À felicidade na liberdade ou à felicidade na ausência de liberdade"

pelos homens, revela como o eu se apresenta: suas cicatrizes, seus fragmentos, na luta para que não sejam apenas mais e tão somente cicatrizes e fragmentos. Através da tradição inscrita por este conhecimento, os homens sempre apresentam o que é melhor possível, ou seja, melhor é impossivel dado as condições da sociedade. O que Freud pôde descrever são indícios, marcas que apontam os limites e indicam a crítica, mas não o próprio indivíduo. Resistência e crítica dirigida ao eu burguês que naquilo que sofre, pede por liberdade. Contudo, isto não é, sem esforço, consciente; está associado ao eu dominado. É o mesmo que limita e possibilita a expressão deste estado: que ao desvelar o sofrimento requer a libertação do que o faz sofrer.

O neurótico, pelo exagero, revela o desconforto, o sofrimento. Estes são sintomas, sinais, de que algo não vai bem. A psicologia quando contribui para naturalizar e psicologizar os sintomas da neurose cede às tendências regressivas, negando a esses sua expressão - o mal-estar - como processo da adaptação social. Colabora com a dominação ao estender um véu sobre a realidade e atribuir ares humanos ao reificado. "Qualquer tipo de psicologismo, o partir despreocupadamente do indivíduo, é ideologia. Transmuta a forma individualista da socialização em uma determinação extra-social e natural do indivíduo" (Adorno, 1986, pp.48-49 e 1991, p.157).

Assim, se a psicanálise pôde trazer elementos de crítica ao indivíduo burguês, o mesmo não pode ser dito da prática terapêutica. Esta, deve ser denunciada por cumprir a função de ajustar o homem a uma sociedade injusta, de ter como objetivo integrar o homem a uma sociedade que o leva a sofrer. Os sintomas são respostas aos sofrimentos suscitados pela sociedade; opor-se aos tipos que encarnam estes sintomas sem levar em conta as condições sociais e a necessidade de sua alteração os impelem à adesão irracional aos apelos dos movimentos de massas. A psicologia aplicada, ao se apresentar de forma afirmativa com intervenções que visem minorar ou mascarar o estado de sofrimentos das pessoas como se isso fosse independente das condições sociais que os determinam, atua diretamente para a manutenção do sofrimento como forma de sustentação dessas mesmas condições objetivas irracionais. Portanto, é ideológico atribuir à psicologia um trabalho direto com o sofrimento pautado por técnicas que mantêm e disseminam formas de ilusão; ao contrário, ao lidar com o sofrimento, a psicologia deve indicar e denunciar o que leva a este estado: as condições sociais que impedem a existência do indivíduo. 
Psicologia \& Sociedade; 14 (1): 123-140; jan./jun.2002

\section{SUJEITO E OBJETO; PRÁXIS E TEORIA}

A psicologia deve, além de fazer a crítica à ideologia - entendida agora como mentira manifesta ${ }^{5}$-, se perguntar que tipos de elementos a ideologia busca nos indivíduos e que tipos de mecanismos dos indivíduos são acionados. Por exemplo, deve-se perguntar até que ponto a neurose, este estado particular de desconforto, está sendo possível. Aqui é revelada a força da psicanálise em seu anacronismo: “(...) até que ponto ainda se justifica toda a distinção psicanalítica entre o consciente e o inconsciente" (Adorno e Simpson, 1994, p.146); se na época de Freud as condições sociais solicitavam configurações psicológicas expressas nos tipos de histeria e neurose obsessiva compulsiva, nas condições atuais predominam a identificação com o delírio paranóico objetivo representada pela síndrome do pânico e pelas generalizações de certos estados sob o nome de depressão e/ou distúrbio bipolar; se o próprio processo de introjeção está danificado pela socialização total apresentam-se, cada vez mais, tipos de sujeitos sem subjetividade ${ }^{6}$. O conhecimento que a psicanálise trouxe dá medidas do quanto de regressão há na sociedade da adaptação imediata, na sociedade industrial. A dominação está tão próxima da consciência que a energia gasta para aderir ao existente é excessiva. É feito um esforço intenso para aceitar o que é imposto. Contudo, a energia é a mesma: tanto para se tornar homem ou se manter como inseto (Adorno e Simpson, 1994, p.146).

Apesar de ser um conceito posterior à sociedade, portanto, categoria social, o indivíduo, ao trazer o social como sua substância, é também o seu contrário, pois traz a possibilidade de fazer substância de si mesmo7. "As diferenças específicas dos indivíduos são tanto estigmas da pressão social como cifras da liberdade humana" (Adorno, 1986, p.43 e 1991, p.148).

O universal é social, o que the confere objetividade. Se o particular é determinado pelo universal, o universal só existe por meio dos particulares. É na contraposição que se permite a singularidade, porém esse processo não está ocorrendo; o que se tem é uma aparência de singularidade. Nessa sociedade a identidade é ideologia - mantém o mito - por representar a integração a uma sociedade injusta. A lógica da identidade leva os homens à compulsão de serem sempre os mesmos, negando-lhes a diferenciação e a própria característica humana: de ser diverso no genérico; ser indivíduo. Aquilo que é visto como repetição é do sujeito e não do objeto, o sujeito projeta a repetição para proporcionar o seu controle. Indicar a repetição como um fenômeno social é denunciar o processo no 
Franciscatti, K.V.S. "À felicidade na liberdade ou à felicidade na ausência de liberdade"

qual o que é definido em sua distinção vem se prendendo como mera repetição: o indivíduo.

No mito há a representação do indiferenciado, nele tudo se repete como sendo o mesmo. Através do esclarecimento, os homens podem se diferenciar, tornar-se homem, ser dono do seu próprio destino; diferenciar-se da regularidade projetada na natureza. Não há necessidade dos homens repetirem-se tal como os mitos solicitavam. Fazia parte da função atribuída aos mitos escamotear a distinção entre homem e natureza. Trata agora de superar a dominação tanto sobre a natureza externa como interna e permitir que a diferença seja compartilhada. Porém, a pretensa diferença nos dias de hoje esconde o poder ao servir somente à autoconservação: manifesta a desigualdade social.

A consciência da liberdade é condição fundamental para a existência da própria liberdade. Neste mundo cabe, do muito que já representa, conhecer os limites da prisão. Pois, se a constatação de que estamos sob a ordem estrita da autoconservação é certa, vale da mesma forma a constatação que só a reflexão pode resistir.

Na reflexão do sujeito, que é também objeto, se encontra o caminho da liberdade. As impressões do sujeito no ato do conhecimento não são casuais, são suscitadas pelo objeto. No conhecimento há de se respeitar a primazia do objeto, porém "a primazia do objeto é a 'intentio obliqua' da 'intentio obliqua', não a requentada 'intentio recta'; o corretivo da redução subjetiva, não a denegação de uma participação subjetiva" (Adorno, 1995b, p.188; aspas no original). É a reflexão sobre a reflexão que possibilita a correção da participação subjetiva, o controle da projeção ${ }^{8}$. Devese repor o que a redução do método científico elimina: o sujeito. No conhecimento é preciso - necessário e certo - mais sujeito ${ }^{9}$ que, por ser mediação social, tem sua objetividade. $\mathrm{O}$ que se pede é a auto-reflexão: o homem por ser sujeito deve voltar a si mesmo como objeto para conhecer e ir além de suas determinações, nisso também realiza fragmentos da liberdade. Assim, se objetividade humana é a sua subjetividade, para permitir maior objetividade ao conhecimento a psicologia deve trazer como tarefa a reflexão sobre a subjetividade.

Onde impera a necessidade não há liberdade, esta só é possível num mundo onde não haja ameaça. Enquanto os ditames da autoconservação forem exercidos - apesar de já serem evitáveis - a possibilidade da liberdade estará suspensa. Sob as condições da autoconservação todos vão lutar para garantir a própria sobrevivência.

"O mecanismo da adaptação às endurecidas condições é, ao 
$\overline{\overline{ }}$ Psicologia \& Sociedade; 14 (1): 123-140; jan./jun.2002

mesmo tempo, um mecanismo de endurecimento do sujeito em si: quanto mais se ajusta à realidade, tanto mais se converte em coisa, menos vai vivendo, mais absurdo se torna esse seu 'realismo', que tudo destrói, por meio do qual intervém propriamente a razão autoconservadora, e que sucessivamente ameaça à vida pura". (Adorno, 1986, p.52 e 1991, p.164; aspas no original)

Liberdade implica também livrar-se do trabalho que permitiu a superação da autoconservação:

"A práxis nasceu do trabalho. Alcançou seu conceito quando o trabalho não mais se reduziu a reproduzir diretamente a vida, mas sim pretendeu produzir as condições desta: isto colidiu com as condições então existentes. $\mathrm{O}$ fato de se originar do trabalho pesa muito sobre toda práxis. Até hoje, acompanha-a o momento de não-liberdade que arrastou consigo: que um dia foi preciso agir contra o princípio do prazer a fim de conservar a própria existência; embora o trabalho, reduzido a um mínimo, entretanto não mais precisasse continuar acoplado à renúncia". (Adorno, 1995c, p.206)

O trabalho foi, pelas contingências históricas, condição da liberdade. $\mathrm{O}$ acúmulo da produção possibilitou o tempo livre. E, uma vez que as condições passaram a existir, pela acumulação dos bens da civilização, o trabalho, expressão de não-liberdade, deixou de ser necessário em sentido estrito, reduziu-se a uma pequena parcela. O que o trabalho pôde produzir traz frações de liberdade, no entanto a manutenção de suas relações anacrônicas não. Nesse sentido, a liberdade se impõe - em seu duplo sentido de tornar obrigatório/instituir e enganar/iludir. Dito de outra forma, a liberdade reside e se esconde nos avanços da civilização ${ }^{10}$. E por existir como negação determinada não dá para saber como é mas sim como não é; ter consciência da prisão ${ }^{11}$.

O que existe de progresso não pode ser negado: as melhorias materiais da vida são visíveis, difíceis são as considerações, não menos verdadeiras, de que não são comuns a todos os homens e de que não tragam liberdade e felicidade. Por trazer em si a dominação trata-se de um progresso que continua, reiteradamente, a negar as gratificações possíveis em uma civilização avançada; de um progresso qualificado pela introjeção do sacrifício como meio de vida, possível e prazeroso por se alimentar em tendências sadomasoquistas, e aquele que se sacrifica passa a cobrar o sacrifício dos demais. 
Franciscatti, K.V.S. "À felicidade na liberdade ou à felicidade na ausência de liberdade"

A atividade de pensar foi permitida a partir do momento que a acumulação aconteceu, pois deixou de ser premente a garantia da existência material. No cotidiano imerso no domínio da necessidade não há pensamento mas sim adesão. É requerido a todo momento agir, respostas à obsessão do fazer sem considerar o que é possível. "O ativismo é regressivo. Cativado por aquela positividade que há tanto tempo faz papel de armadura para a debilidade do Eu, recusa-se a refletir sobre a sua própria impotência" (Adorno, 1995c, p.223). Para não entrar no jogo das determinações é fundamental a teoria para delimitar a ação: criticar é apontar os limites. É a teoria que permite ir além do imediato e é este que a fundamenta. "O não-obtuso vem a ser defendido pela teoria. Apesar de toda sua não-liberdade, ela é, num mundo [não] livre, lugar-tenente da liberdade" (op. cit., p.207) ${ }^{12}$.

\section{FELICIDADE: NA LIBERDADE OU EM SUA AUSÊNCIA?}

Freud já suspeitava da existência de uma parcela de "natureza inconquistável"13. Mas, para além do que esse autor pôde elaborar, cabe reforçar, com base nos frankfurtianos, o seu caráter de indagação - será inconquistável? - e nomeá-la mais diretamente: é a dominação a inimiga da liberdade e da felicidade. Quando os homens dominam exercem a natureza estrita pois esta é da sua esfera, a não-dominação é característica da liberdade. Então, faz-se necessário superar a última parcela de natureza: a própria necessidade de dominação ${ }^{14}$; dominação dos homens sobre a natureza, sobre outros homens e sobre si mesmos. Nesse sentido, a liberdade indica a não necessidade da repetição para garantir a sobrevivência, a possibilidade de viver em demasia (sobra, excesso, sobejo).

Adorno escreve: "se fosse permitido especular sobre o estado de reconciliação, não caberia imaginá-lo nem sob a forma de indiferenciada unidade de sujeito e objeto nem sob a de sua hostil antítese; antes, a comunicação do diferenciado" (1995b, p.184). E ainda indica: "paz é um estado de diferenciação sem dominação, no qual o diferente é compartido" (op. cit., p.184). Assim, liberdade é um estado onde a paz possa existir, onde o medo possa ser elaborado e a reconciliação com a natureza ocorra de forma diferente da presente na dominação, que os homens, conscientes de si e do outro, relacionem-se com a natureza como um outro diferenciado. Cada vez é mais permitido assolar menos a natureza, tanto a própria quanto a alheia; todavia há a intensificação desse processo. A reconciliação passa pela diferenciação, pelo reconhecimento do outro e por abrir mão, dispen- 
Psicologia \& Sociedade; 14 (1): 123-140; jan./jun.2002

sar, o poder: ao outro externo (natureza externa) não ver como perpétua exploração e dominação; ao outro interno (natureza interna) fazer justiça à pulsão através da cultura, não como controle mas sim realização alterada; aos outros (homens) buscar contato e a realização da felicidade.

Segundo Freud (1974), a sexualidade constitui o protótipo do comportamento humano, é "o amor sexual" que fornece "(...) um modelo para a nossa busca da felicidade" (p.101). A sexualidade, dessa forma, é entendida como vida: tem sua base no ato sexual e como pulsão inibida em sua finalidade, mas ainda pulsão, amplia sua manifestação a outras esferas do relacionamento ao mesmo tempo que permite a preservação e a particularização dos objetos amados. Tal entendimento coloca a relação sexual para além da reprodução e, ao ultrapassar essa finalidade, passa a definir a sexualidade como algo em si.

Desta forma, liberdade e felicidade coincidem: expressam a busca que vai além da autoconservação e que caracteriza aquilo que é humano; expressam a possibilidade de viver a vida como fim em si mesma. Dizer mais que isso é correr o risco de aprisionamento, se é que já não é. Porém, não o fazer é perpetuar a injustiça do que pôde ser formulado, principalmente por e a partir de Marx e Freud (e, neste texto, em referência direta aos frankfurtianos Adorno, Horkheimer e Marcuse). Reafirmar tais formulações presentes no que pôde ser produzido de conhecimento também revela cicatrizes, marcas do sofrimento que ficam aquém da percepção, e fragmentos, que não são mas indicam a própria possibilidade de realização. Fora esses indícios, não restam dúvidas, não há esperanças de realização da liberdade e felicidade nesta forma de sociedade.

Felicidade e liberdade são, portanto, distinções humanas ${ }^{15}$, presentes na promessa do indivíduo tal como postulado pelo esclarecimento: produto e antítese social. Distinções que lutam mas que não estão sendo realizadas e que a psicologia, por não levar em conta tal contradição, contribui para obstar. A adesão à violência é representada diretamente pelas pretensas dificuldades na definição do objeto de estudo da psicologia: ao fechar-se para a experiência e a reflexão em seu trabalho científico, os psicólogos tendem a abandonar seu objeto - o indivíduo - ao invés de enfrentar os obstáculos à sua realização.

Como exposto, o conhecimento tem vinculação direta a um interesse social objetivo: a emancipação humana. $\mathrm{O}$ esclarecimento, em seus elementos progressivos e regressivos, obstruem e capacitam o homem na realização da autodeterminação. Ser objeto de si através da reflexão e conhecer suas determinações é avançar nesse sentido. Portanto, deve-se cri- 
Franciscatti, K.V.S. "À felicidade na liberdade ou à felicidade na ausência de liberdade"

ticar a utilização de qualquer conhecimento para justificar o não enfrentamento das limitações dessa sociedade. Deve-se criticar as ilusões que mascaram a atual impotência humana.

Cada vez mais no particular o todo é visível; isso acontece pela simplificação da sociedade em marcha constante à integração total: "o inconsciente, protegido cuidadosamente do olhar do ego graças à manipulação, coincide felizmente em sua pobreza e indiferenciação com a estandardização e com o mundo administrado" (Adorno, 1986, p.52 e 1991, p.163). Assim,

"Oportunos são aqueles tipos que não têm um ego nem atuam de maneira propriamente inconsciente, mas sim que reproduzem o traço objetivo à maneira de reflexo. Praticam em conjunto um ritual absurdo, seguem o ritmo compulsivo da repetição, empobrecem afetivamente: com a destruição do ego aumentam o narcisismo ou seus derivados coletivistas". (Adorno, 1986, p.74 e 1991, p.201)

A vitória da sociedade sobre o indivíduo corresponde à vitória do id sobre o ego. Freud, ao formular a segunda tópica do aparelho psíquico - como id, ego e superego alterando a formulação da primeira que somente diferenciava três sistemas como inconsciente, pré-consciente e consciente - pedindo por harmonia entre as três instâncias, cede e admite o controle irracional para manter a ordem social. Diante disto não tem erro: "a brutalidade do exterior, a igualadora sociedade total, detém a diferenciação e se aproveita do núcleo primitivo do inconsciente. Ambas concordam na aniquilação da instância mediadora" (op. cit., p. 74 e op. cit., p. 201).

Com isso, "a psicanálise, em sua forma autêntica e historicamente superada, (....)" não conseguiu conceber que "o ego, como algo surgido, é um fragmento [marca] de pulsão, e por sua vez outra coisa" e assim, "ao revogar a diferenciação que se chama ego, se converte no que menos queria: um fragmento [marca] da regressão"; não dando ouvidos à evidência que “(...) a essência não é o abstratamente repetido, mas sim o geral como diverso" (op. cit., pp. 74-75 e op. cit., p. 201-203).

Isso vale tanto para a psicanálise em seu conhecimento histórico como para toda a psicologia que deveria, mas não faz, eleger o ego como conceito dialético, “(...) psíquico e não psíquico, um fragmento [parte] de libido e representante do mundo" (op. cit., p. 62 e op. cit., p. 180), instância da adaptação e da crítica à adaptação - seu principal conceito na luta pela existência de seu objeto de estudo. O indivíduo apresenta-se ain- 
Pscologia \& Sociedade; 14 (1): 123-140; jan./jun.2002

da como negação determinada: contradição existente que já indica a transformação.

Alcançar tanto a liberdade como a felicidade faz parte de uma tarefa objetiva, possível quando a adaptação estrita não for mais necessária. A frase de Adorno, que pergunta sobre o objetivo da análise mas que pode se estender para a psicologia, já mostra a redução do seu objetivo científico ao antagonismo social e indica o encerramento a um falso dilema: a felicidade na liberdade não está sendo possível pelas atuais formas de organização social; felicidade na ausência de liberdade é um simulacro, não existe, porque ambas coincidem em sua realização. Entretanto, sua verdade está em expor aquilo mesmo que deve ser superado, expor seu objetivo como seu próprio fim.

Todo cuidado é pouco. Pois, falar de felicidade na liberdade nos dias de hoje é também prestar serviço ao que se apresenta. Cabe conhecer os limites desta prisão e não divagar como ela não seria, como seria a vida livre. Ou seja, falar da liberdade e da felicidade de maneira abstrata sustenta os obstáculos da realidade. Deve-se ter como atividade pensar o existente e suas possibilidades traídas e esquecidas.

Resta reconhecer antes de tudo: ante à esmagadora opressão os homens encontram-se cativos e impotentes. E resistência significa exatamente enfrentar aquilo que leva à impotência não no sentido do endurecimento mas do reconhecimento da fragilidade de cada um e de todos. Reconhecer e reiterar um dos elogios de Adorno a Freud é compartilhar com os dois buscando combater aquilo que causa o sofrimento e não manter as formas de ilusão.

\section{REFERÊNCIAS BIBLIOGRÁFICAS}

ADORNO, Theodor W. Acerca de la relación entre Sociologia y Psicologia.(1955) In: JENSEN, H. (org.) Teoria crítica del sujeito. Buenos Aires: Ed. Sieglo XXI, 1986. pp.36-83. [Postscriptum de 1965 ou 1966 pp.77-83.]

De la relacion entre sociologia y psicologia.(1955) In.

Actualidad de la filosofía. Barcelona: Ediciones Paidós, 1991. pp.135204.

Educação após Auschwitz. (1965) In. Palavras e sinais; modelos críticos 2. Petrópolis/RJ: Vozes, 1995a. pp.104-123. 
Franciscatti, K.V.S. "À felicidade na liberdade ou

à felicidade na ausência de liberdade"

Sobre sujeito e objeto. (1969) In. Palavras e sinais; modelos críticos 2. Petrópolis/RJ: Vozes, 1995b. pp.181-201.

Notas marginais sobre teoria e práxis. (1969) In. Palavras e sinais; modelos críticos 2. Petrópolis/RJ: Vozes, 1995c. pp.202229.

ADORNO, Theodor W. e HORKHEIMER, Max. Dialética do esclarecimento; fragmentos filosóficos. (1947) Rio de Janeiro: Jorge Zahar Editor, 1994. 254p.

ADORNO, Theodor W. e SIMPSON, G. Sobre música popular.(1941) In.

Theodor W. Adorno; grandes cientistas sociais. Org. Gabriel Cohn 2.ed. São Paulo: Editora Ática, 1994. pp.115-146.

CROCHÍK, José Leon. Notas sobre a psicologia social de T. W. Adorno. Psicologia \& Sociedade. São Paulo, v.8, n.1, pp.43-62, jan./jun., 1996.

FREUD, Sigmund. O mal-estar na civilização.(1930[1929]) Edição Standard Brasileira das Obras Psicológicas Completas. Rio de Janeiro: Imago, 1974. V. XXI, pp.73-171.

FRANCISCATTI, Kety Valéria Simões. Violência, preconceito e propriedade; um estudo sobre a violência a partir da Teoria Crítica da Sociedade. São Paulo: 1998. 165p. Dissertação (Mestrado em Psicologia Social) - PUCSP.

HORKHEIMER, Max e ADORNO, Theodor W. Temas básicos da Sociologia. (1953/1954) São Paulo: Cultrix/USP, 1973. 205 p.

\section{NOTAS}

${ }^{1} \mathrm{O}$ título é uma citação de Adorno do texto Acerca de la relación entre Sociologia y Psicologia escrito em 1955 (foram utilizadas para as citações duas versões do espanhol: Adorno, $1986 \mathrm{e}$ 1991; as traduções são da autora). Esse ensaio traz uma versão ampliada do texto apresentado no VIII Encontro Regional da ABRAPSO-SP, "O Século XXI: Os Dilemas e Perspectivas para a Psicologia Social," no dia 12 de outubro de 2000, e representa um momento parcial na formulação desse tema. Portanto, é necessário dimensionar tanto o caminho percorrido como o 
Psicologia \& Sociedade; 14 (1): 123-140; jan./jun.2002

que falta percorrer. Aqui são considerados alguns textos de Freud, Adorno e Horkheimer como um primeiro momento de estudos que posteriormente serão ampliados com o que pôde ser elaborado por outros autores, em especial Marcuse, processo que deve ser feito de maneira ponderada para resguardar as diferenças de cada autor.

${ }^{2}$ Para maiores detalhes consultar Horkheimer e Adorno, 1973, Cap. II Sociedade, pp.25-44. Os autores escrevem: "No seu mais importante sentido, entendemos por 'sociedade' uma espécie de contextura formada entre todos os homens e na qual uns dependem dos outros, sem exceção; na qual o todo só pode subsistir em virtude da unidade das funções assumidas pelos coparticipantes, a cada um dos quais se atribui, em princípio, uma tarefa funcional; e onde todos os indivíduos, por seu turno, estão condicionados, em grande parte, pela sua participação no contexto geral" (p.25; aspas no original). No decorrer do texto, analisam os diferentes aspectos que o conceito de sociedade foi adquirindo e como esse sistema vem, historicamente, estabelecendo funções autonomizadas em relação aos homens, os quais não mais introjetam os papéis sociais mas sim passam a reproduzí-los de forma direta, que é a mais mediada de todas, através do processo de "socialização total".

${ }^{3}$ Ver ${ }^{A}$ dorno 1986, p.50 e 1991, pp.159-160.

${ }^{4}$ Conceito de Leibniz, presente na obra de Freud, que postula todas as coisas como uma unidade dinâmica dotada de princípios internos próprios, capazes de só se comunicarem com mônadas superiores. Um texto fundamental para a discussão sobre esses aspectos e também base das reflexões presentes nesse ensaio é Notas sobre a psicologia social de T. W. Adorno (Crochík, 1996)

${ }^{5}$ Segundo Horkheimer e Adorno (1973, pp.184-205), a sociedade industrial provocou uma mudança no conceito tradicional de ideologia, que nisso parece perder seu objeto. O que resta é apenas uma adaptação direta, mas sempre mediada, à sociedade industrial, incentivada também pelos produtos de sua indústria cultural. A tendência da ideologia da cultura de massa é de "converterse naquilo mesmo que é", obstruindo qualquer tipo de transcendência e de crítica, oferecendo modelos de comportamento para a manutenção das condições existentes. Porém, os autores, apontam: "os homens adaptam-se a essa mentira mas, ao mesmo tempo, enxergam através de seu manto. A celebração do poder e a irresistibilidade do mero existir são as condições que levam ao desencanto. A ideologia já não é um envoltório mas a própria imagem ameaçadora do mundo. Não só pelas suas interligações com a propaganda mas também pela sua própria configuração, converte-se em terror. Entretanto, precisamente porque a ideologia e a realidade correm uma para a outra; porque a realidade dada, à falta de outra ideologia mais convincente, converte-se em ideologia de si mesma, bastaria ao espírito um pequeno esforço para se livrar do manto dessa aparência onipotente, quase sem sacrifício algum. Mas esse esforço parece ser o mais custoso de todos" (p.203). Assim, a ideologia mudou de função: se antes, na forma liberal, era uma maneira parcial de se relacionar com a realidade, contendo alguns elementos da mesma, uma meia-verdade, em sua versão moderna se apresenta como uma mentira manifesta, chegando ao cinismo. Porém, a maior resistência parece estar no reconhecimento dessa transparência. Se a ideologia está desta forma é porque a verdade nunca esteve tão próxima da consciência. Portanto, esse cinismo manifesto não deixa de ser produto do esclarecimento. Um esclarecimento que não deixa de temer a verdade que está ao seu alcance, de realizar-se como esclarecimento. A realidade que não se oculta necessita de mecanismos psíquicos para não aparecer. Então, para aderir a uma mentira cínica faz-se necessário a movimentação de mecanismos psicológicos. Paga-se um alto preço por conviver tão próximo a algo temido e escondido. No texto Sobre música popular (Adorno e Simpson, 1994) os autores analisam os mecanismos acionados pelo 
Franciscatti, K.V.S. "À felicidade na liberdade ou à felicidade na ausência de liberdade"

indivíduo para deixar-se enganar pelos artifícios da indústria cultural que reproduz constantemente o mesmo tipo de música.

${ }^{6}$ Ver Adorno e Horkheimer, 1994, p.160.

${ }^{7}$ Para aprofundar essa discussão consultar Horkheimer e Adorno, 1973, Cap. III Indivíduo, pp.45-60.

${ }^{8}$ Ver especialmente Adorno e Horkheimer, 1994, pp.174-186, onde os autores analisam o VI elemento do anti-semitismo.

${ }^{9}$ Ver Adorno, 1995b, p. 191.

${ }^{10}$ Horkheimer e Adorno (1973, pp.93-104), ao analisarem os conceitos de "civilização" e "cultura", criticam a separação existente para alguns teóricos que atribuem à primeira as realizações materiais e à segunda as realizações do "espírito" (intelectuais), e concordam com a não diferenciação entre os termos destacando, com uma "sensação de alívio", uma longa citação de Freud presente no O futuro de uma ilusão. No entanto, os autores também alertam sobre o processo de separação desses dois elementos que vem se desenrolando na realidade e, portanto, a necessária tensão entre seus significados. Nesse sentido, concluem ao final do texto: "o que toda a cultura nada mais fez, até hoje, do que prometer, será realizado pela civilização quando esta for tão livre e ampla que não exista mais fome sobre a Terra" (p.99).

${ }^{11}$ É importante indicar que a propriedade é fundamental para a existência do indivíduo. É a apropriação da cultura que permite a constituição do psicológico como terreno distinto daquilo que o possibilitou. $\mathrm{O}$ indivíduo - conceito que diz daquele que é próprio, proprietário de si mesmo, autodeterminado, autoconsciente - somente é possível pela apropriação particular (subjetiva) dos bens culturais, processo que está impedido pela forma capitalista de organização social. Por isso, a propriedade tal como se apresenta mantém a violência, obstruindo a liberdade e a felicidade que poderiam proporcionar (Ver Franciscatti, 1998).

${ }^{12} \mathrm{Na}$ versão em português não consta a palavra "não", mas a mesma foi acrescentada na citação (entre colchetes) por sua ausência ser considerada um erro de impressão tendo como base a confrontação com a edição argentina do livro Consignas, 1973, p.163, Buenos Aires: Amorrortu editores.

${ }^{13}$ Freud, 1974, p. 105: "contudo, quando consideramos o quanto fomos mal sucedidos exatamente nesse campo de prevenção do sofrimento, surge em nós a suspeita de que também aqui é possível jazer, por trás desse fato, uma parcela de natureza inconquistável - dessa vez, uma parcela de nossa própria constituição psíquica".

${ }^{14}$ Ver Adorno e Horkheimer, 1994, pp.51-52.

${ }^{15} \mathrm{O}$ próprio Freud, apesar de afirmar o contrário, trazia elementos para revelar o quanto de mitológico há na idéia de maiores felicidade e liberdade no passado. Ver Freud, 1974, p.116 e p.137.

Kety Valéria Simões Franciscatti é mestre e doutoranda em Psicologia Social pela PUC/SP. O endereço eletrônico da autora

Kety Valéria Simões Franciscatti é: k.francis@uol.com.br

"À felicidade na liberdade ou á felicidade na ausência de liberdade"

Artigo aceito por São Paulo

Recebido: $17 / 5 / 2002$

$1^{\text {a }}$ revisão: $18 / 6 / 2002$

$2^{\mathrm{a}}$ revisão: 1/7/2002

Aceite final: 7/8/2002 